circulatory rate and oxygenation after birth. The role of SI on major neonatal outcomes remains controversial.

Methods We conducted a systematic review and meta-analysis of randomised clinical trials that evaluated the effects of SI and IPPV on mortality and bronchopulmonary dysplasia (BPD). Descriptive and quantitative information was extracted; relative risk (RR) and risk difference (RD) estimates were synthesised under a random-effects model. Heterogeneity was assessed using the $\mathrm{Q}$ statistic and $\mathrm{I}^{2}$.

Results Pooled analysis of 4 trials $(n=611)$ showed significant reduction in the need of mechanical ventilation within $72 \mathrm{~h}$ after birth $(\mathrm{RR}=0.87$ [0.77-0.99], $\mathrm{RD}=-0.10$ [-0.17, -0.03]. numberneeded-to-treat $=10$ ) in preterm infants treated with an initial SI compared to IPPV. However, significantly more infants treated with SI received treatment for patent ductus arteriosus $(\mathrm{RR}=1.27$ [1.05-1.54], $\mathrm{RD}=0.09$ [0.02, 0.16], number-neededto-harm=11). There were no differences in BPD, death at latest follow-up, the combined outcome for BPD or death, and other major neonatal outcomes between the two approaches.

Conclusions Compared to IPPV, preterm infants initially treated with SI at birth required less mechanical ventilation within $72 \mathrm{~h}$ after birth with no improvement in the rate of BPD and/or death. SI should currently only be used in randomised trials until future studies demonstrate the efficacy and safety of this lung aeration manoeuvre.

\section{PO-0672 CORD BLOOD OSTEOCALCINE, LEPTIN AND TNF? LEVELS IN GESTATIONAL DIABETIC PREGNANCIES}

${ }^{1} \mathrm{C}$ Dalkan, ${ }^{2} \mathrm{M}$ Uncu, ${ }^{1} \mathrm{~N}$ Galip, ${ }^{3} \mathrm{EYUP}$ Yayci, ${ }^{1} \mathrm{~N}$ Bahceciler, ${ }^{1} \mathrm{I}$ Akman. ${ }^{1}$ Pediatrics, Near East University, Nicosia, Cyprus; ${ }^{2}$ Clinical Biochemistry, Near East University, Nicosia, Cyprus; ${ }^{3}$ Obstrectic and Gynecology, Near East University, Nicosia, Cyprus

\subsection{6/archdischild-2014-307384.1313}

Aim To compare cord blood osteocalcin, leptin and TNF $\alpha$ levels in gestational diabetic and normal pregnancies.

Method 191 deliveries were included in this research. 41 $(21.5 \%)$ of pregnancies were gestational diabetic and 159 (78.5\%) of pregnancies were normal. Cord blood osteocalcin, leptin and TNF $\alpha$ levels were compared.

Results There was no significant difference among birth weights (p:0.409), heights (p:0.07), head circumferences ( $p$ 0.201), gender (p:0.4), gestational weeks (p:0.201), ponderal index (0.564) between groups. There was no significant difference between groups regarding pregnancy complications. However, hypothyroidism was more common in gestational diabetic group $(\mathrm{p}:<$ $0.001)$. In addition, hypoglycemia was more common in gestational diabetic group (p:0.047).

Gestational diabetic group's cord blood osteocalcin levels were higher than in non diabetic group (p:0.037). Cord blood TNF $\alpha$ (p:0.813) and leptin average levels (p: 0,212) were not statistically different. Osteocalcin, leptin and TNF $\alpha$ levels were not statistically different between boys and girls.

Discussion Osteocalcin; originating from bones, increases insulin sensitivity in peripheral organs and insulin secretion. Leptin is known to inhibit insulin and osteocalcin secretion. Osteocalcin level increase in gestational diabetic group, may be related to osteocalcin regulation of blood glucose levels. Cord blood leptin and TNF $\alpha$ levels showed no significant difference between groups, probably due to proper regulation of cord blood glucose levels during gestation.

\section{P0-0673 IMPROVING QUALITY OF CARE FOR ELBW IN OUR NEONATAL UNIT: AN INTERDISCIPLINARY PROJECT}

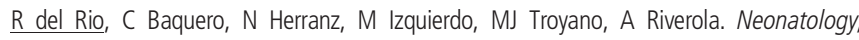
Hospital Sant Joan de Deu, Barcelona, Spain

\subsection{6/archdischild-2014-307384.1314}

Background Our hospital attends 90 VLBW and 40 ELBW infants/year. Vermont Oxford Network is used as benchmarking tool.

Aims To improve quality of care delivered to ELBW's during the first week of life. Primary outcome is IVH reduction. Secondary outcomes are mortality, late onset sepsis (LOS) and ROP reduction.

Methods An interdisciplinary group leaded by 4 nurses and 3 neonatologists was created in January 2012. Management of ELBW infants was reviewed to identify weaknesses and strengths. The original team was then divided into subgroups that worked together for problem resolution. 2 gynaecologists, 1 surgeon and 60 members of the neonatal unit were involved (70\% of nurses and $90 \%$ of neonatologists). Specific actions were developed for 1 . Delivery Room: plastic wrapping, delayed chord clamping and blood sampling; 2. Admission and first golden hours: temperature and humidity targets, blood sampling, calostrum administration, enemas and positional care. Results were transmitted in oral sessions and written guidelines to the rest of the Unit.

Results No changes were found in 2012 compared to the last five years. However in 2013, a decrease was seen in inborns in severe IVH (from 11,6 to $10,9 \%$ ), LOS $(15,8 \%$ to $9,8 \%)$ and severe ROP (10,1 to $5,9 \%)$.

Conclusions A high percentage of the neonatal unit has been involved in this project. Short term outcomes have improved for the first time last year. A qualitative change difficult to quantify has also been produced. Caution must be taken when interpreting numerical results as they reflect improvement of only one year.

\section{PO-0674 INCIDENCE OF INDIRECT HYPERBILIRUBINEMIA AT NEWBORN, ASSOCIATED PATHOLOGY AND THE ROLE OF PHOTOTHERAPY}

${ }^{1} \mathrm{C}$ Dobrin, ${ }^{2} \mathrm{D}$ Davidescu, ${ }^{3} \mathrm{R}$ Burca, ${ }^{1} \mathrm{O}$ Falup-Pecurariu. ${ }^{1}$ Newborn, Transilvania University Faculty of Medicine University Childrens Hospital, Brasov, Romania; ${ }^{2}$ Pulmonology, Transilvania University Faculty of Medicine University Childrens Hospital, Brasov, Romania; ${ }^{3}$ Laboratory, Transilvania University Faculty of Medicine University Childrens Hospital, Brasov, Romania

\subsection{6/archdischild-2014-307384.1315}

Background Indirect hyperbilirubinemia at newborn is a distinct and various epidemiological described entity, having multiple causes and mechanisms, in which bilirubin level rises to 15-20 $\mathrm{mg} \%$.

Aim of the study The aim of the study was to evaluate the incidence of jaundice with indirect bilirubin at newborns admitted at the Newborn Department of the Childrens Clinic Hospital from Brasov, Romania. As secondary objectives we considered the associated pathology along with the usefulness of phototherapy.

Patients and methods We undergone a retrospective study on 1020 patients admitted at our hospital during one year period 1st January 2012-31st December 2012. We have evaluated 
demographic data, clinical and laboratory data along with the prescribed therapy.

Results From the 1020 studied cases in 260 there was a diagnosis of indirect hyperbilirubinemia, associated pathology consisted of urinary tract infection in 15 cases, piodermatitis in 12, otitis media in 7 , acute diarrhoea in 14 cases and severe dehydration in 9 cases.

Only one case complicated with kernicterus. From the 260 cases only 60 had phototherapy in the treatment schedule.

Conclusion we have shown that one quarter of the jaundice at newborn is due to indirect hyperbilirubinemia and that phototherapy is still a useful treatment.

\section{PO-0675 PREVALENCE OF MUTATION C.11864G $>$ A (P. TRP3955X) IN THE USH2A GENE IN PATIENTS WITH USHER II SYNDROME FROM VOLGA-URAL REGION OF RUSSIA}

\begin{abstract}
${ }^{1} \mathrm{~L}$ Dzhemileva, ${ }^{1} \mathrm{~S}$ Lobov, ${ }^{1} \mathrm{D}$ Kuznetzov, ${ }^{2} \mathrm{R}$ Valiev, ${ }^{3} \mathrm{~A}$ Mukminov, ${ }^{1} \mathrm{~V}$ Ahmetova, ${ }^{1} \mathrm{R}$ Khusainova, ${ }^{1} \mathrm{~A}$ Karunas, ${ }^{1}$ I Khidiyatova, ${ }^{4} \mathrm{~N}$ Barashkov, ${ }^{4} \mathrm{~S}$ Fedorova, ${ }^{5} \mathrm{O}$ Posukh, ${ }^{1} E$ Khusnutdinova. ${ }^{1}$ Human Molecular Genetics, Instute of Biochemistry and Genetics USC RAS, Ufa, Russia; ${ }^{2}$ Human Molecular Genetics, Department of Genetics and Fundamental Medicine Bashkir State University, Ufa, Russia; ${ }^{3}$ Human Molecular Genetics, Ufa Branch FGBI NCC Otorhinolaryngology FMBA of Russia, Ufa, Russia; ${ }^{4}$ Human Molecular Genetics, Laboratory of Molecular Genetics Yakut Scientific Centre of Complex Medical Problems Siberian Branch of the Russian Academy of Medical Sciences, Yakutsk, Russia; ${ }^{5}$ Human Molecular Genetics, Laboratory of Human Molecular Genetics Institute of Cytology and Genetics Siberian Branch of the Russian Academy of Sciences, Novosibirsk, Russia
\end{abstract}

\subsection{6/archdischild-2014-307384.1316}

Usher Syndrome (US) is an autosomal recessive condition characterised by a combination of congenital hearing impairment and retinitis pigmentosa. To date, ten genes have been associated with US, representing up to $90 \%$ of cases. Three types of US are known and differ by onset of the symptoms, severity and progressiveness of deafness and additional vestibular dysfunction. Patients with type II US have congenital bilateral sensor neural hearing loss that is mild to moderate in the low frequencies and severe to profound in the higher frequencies, intact vestibular responses, and bilateral retinitis pigmentosa.

40 unrelated Usher II type families (60 patients) from VolgaUral Region of Russia were studied using genotyping micro array (Usher, Asper-Biotech) for screening 614 mutations in genes CDH23, MYO7A, PCDH15, USH1C, USH1G, USH2A, GPR98, CLRN1, DFNB31 and automatic sequencing of Usher's genes. Diagnosis was based on pedigree data, ophthalmologic, audio logical and vestibular examination.

We revealed homozygous and heterozygous genotypes for the c. $11864 \mathrm{G}>\mathrm{A}$ (p. Trp3955X) mutation (USH2A) in six unrelated families among Russian, Tatar and Chuvash patients with Usher II syndrome. We found four pathogenic mutations in coding region of 8 patients (p. Glu4458fs, p. Trp3955X, p. Glu4078fs, and p. Gly1392X), confirming their clinical diagnosis. The most frequent USH2A gene mutation was c.11864G >A (9/80 alleles; $11,25 \%)$. Mutation c. $11864 \mathrm{G}>\mathrm{A}$ in heterozygous state was also found in one Russian subject out of 1066 examined individuals from 16 various populations of Eurasia: Bashkirs, Tatars, Chuvashes, Udmurts, Komi-Permyaks, and Mordvins, Russians, Belarusians, Ukrainians, Veps, and Karelians, Abkhazians, Kazakhs, Uzbeks, Yakuts, Altaians. Study was supported by grants (No12-0400342_a, No12-04-98520_r_vostok_a, 14-04-97002_r_povolgie_a, 14-04-97007_r_povolgie_a, 14-04-01741_A).

\section{P0-0676 PREDICTIVE VALUE OF POSTNATAL NASOGASTRIC TUBE AND CHEST/ABDOMINAL XRAY FOR ANTENATAL POLYHYDRAMNIOS AND/OR SMALL STOMACH IN THE DIAGNOSIS OF OESOPHAGEAL ATRESIA-TRACHEO-OESOPHAGEAL FISTULA}

1J Egyepong, ${ }^{2} \mathrm{D}$ Bell, ${ }^{3} \mathrm{~T}$ Busari. 'Neonatal Intensive Care Unit, Luton and Dunstable University Hospital, Luton, UK; ${ }^{2}$ Medical School, University College London, London, UK; ${ }^{3}$ Neonatal Intensive Care, Luton and Dunstable University Hospital, Luton, UK

\subsection{6/archdischild-2014-307384.1317}

Introduction Oesophageal atresia $(\mathrm{OA}) \pm$ trachea-oesophageal fistula (TOF) is a rare congenital anomaly which occurs in $\sim 1$ / 3500 total births.

Prenatal diagnosis of OA-TOF is desirable as it may improve patient outcome by optimising the pre- and postnatal management. Therefore, a high prenantal detection rate is desirable. Prenatal ultrasound is one of the modalities used in improving the diagnostic rate. Indirect or non-specific signs of suspected OA-TOF include polyhdramnios (10-20\% of which are associated with fetal abnormalities, one of it being OA-TOF), absent/ small stomach bubble, a blind ending upper oesophageal pouch and observation of fetal swallowing.

In our institution, all foetuses with Isolated polyhydramnios \pm small/absent stomach have postnatal NGT insertion followed by xray if follow up scans remained the same.

Objectives To evaluate the clinical relevance of postnatal NGT insertion followed by xray for prenatal finding of isolated polyhydramnios \pm absent/small stomach bubble in a cohort of newborn babies to assess for the diagnosis of OA-TOF.

Methods

- Retrospective cohort review January2011-March2014 of all foetuses/neonates with suspected EA-TOF on prenatal ultrasound (isolated polyhydramnios [deepest pool $>8 \mathrm{~cm}$, Amniotic Fluid Index $>95$ th percentile for gestational age and/or small/absent stomach bubble] or perinatally identified to have $>1500 \mathrm{mls}$ amniotic fluid and therefore needing postnatal NGT insertion + Xrays pre-feed were identified.

- Course and tip of NGT, stomach-bubble, vertebral anomalies or any other abnormalities detectable on Xray.

- Time taken from birth to when the postnatal Xrays were taken was calculated (time to first feed).

- Babies were also examined for clinical signs of OA-TOF or other abnormalities.

- Clinical data on all OA-TOF cases that were diagnosed postnatally over the same 3 yr period.

- Exclusion - above two features with other any other abnormalities on antenatal scans.

Results

- Total deliveries over period $=17,200$.

- Total no. fulfilling criteria of isolated polyhydramnios \pm small/absent stomach only $=48$.

- No. that resolved antenatally and therefore did not have NGT + Xray assessment postnatally $=12$.

- Total No. who had NGT+Xray assessment $=36$.

- No. without OA-TOF $=35$.

- No. diagnosed with OA-TOF $=1$.

- 7 cases of OA/TEF ( 1 had above 2 features); of which 3 did not have polyhydramnios \pm absent/small stomach; 3 had multiple abnormalities including 2 with polyhydramnios.

- Above two antenatal features had a Sensitivity $=25 \%$; Specificity $=99.8 \%$; positive predictive value $=2.78 \%$ for diagnosis of OA-TOF.

- Mean time for NGT+Xray (away from mothers and before their first $)=156$ mins (range 81-332). 